University of Nebraska - Lincoln

DigitalCommons@University of Nebraska - Lincoln

How people make sense of drones used for atmospheric science (and other purposes): hopes, concerns, and recommendations

Janell C. Walther

Lisa M. PytlikZillig

Carrick Detweiler

Adam L. Houston

Follow this and additional works at: https://digitalcommons.unl.edu/lpz

Part of the Administrative Law Commons, Counseling Commons, Dispute Resolution and Arbitration Commons, Family Law Commons, Juvenile Law Commons, Law and Psychology Commons, Law and Society Commons, Psychology Commons, and the Public Law and Legal Theory Commons

This Article is brought to you for free and open access by the Public Policy Center, University of Nebraska at DigitalCommons@University of Nebraska - Lincoln. It has been accepted for inclusion in Lisa PytlikZillig Publications by an authorized administrator of DigitalCommons@University of Nebraska - Lincoln. 


\title{
How people make sense of drones used for atmospheric science (and other purposes): hopes, concerns, and recommendations
}

\author{
Janell Walther, Lisa PytlikZillig, Carrick Detweiler, and Adam Houston
}

\begin{abstract}
Unmanned aerial systems (UAS) can advance understanding of the atmosphere and improve weather prediction, but public perceptions of drone technologies need to be assessed to ensure successful societal integration. Our qualitative study examines public perceptions of UAS technology, and the associated risks and benefits, for such civilian purposes. We examine how people form perceptions, and discuss the implications of these perceptions for UAS design and regulation. Our study finds the public to be favorable toward UAS used for "noble" purposes. Participant views are informed by popular media, personal experiences, comparisons between technologies, and consideration of the trustworthiness of the users, regulators, and technology itself.

Key words: public perceptions, drones, trust, atmospheric science and weather.

Résumé : Les systèmes aériens sans pilote (UAS) peuvent faire progresser la compréhension de l'atmosphère et améliorer les prévisions météorologiques, mais les perceptions du public à l'égard des technologies de drones doivent être évaluées pour assurer une intégration sociale réussie. Notre étude qualitative examine les perceptions du public à l'égard de la technologie des UAS, ainsi que les risques et les avantages liés à leur utilisation à de tels fins civiles. Nous examinons comment les gens forment leurs perceptions et discutons des répercussions de ces perceptions sur la conception et la réglementation des UAS. Notre étude révèle que le public est favorable à l'utilisation des UAS à des fins " nobles ". Les opinions des participants sont éclairées par les médias populaires, les expériences personnelles, les comparaisons entre les technologies et la prise en compte de la fiabilité des utilisateurs, des organismes de réglementation et de la technologie elle-même. [Traduit par la Rédaction]
\end{abstract}

Mots-clés : perceptions du public, drones, confiance, science atmosphérique et météo.

\section{Introduction}

With recent advances in use of unmanned aerial systems (UAS) for research, consumerism, and entertainment, public interest in drone technology is rising. Because much of the science behind new technologies is publicly funded, some argue the public should have

Received 7 February 2019. Accepted 30 May 2019.

J. Walther and L. PytlikZillig. University of Nebraska Public Policy Center, 215 Centennial Mall South, Suite 401, Lincoln, NE 68508, USA.

C. Detweiler. Department of Computer Science and Engineering, University of Nebraska-Lincoln, 220 Schorr Center, Lincoln, NE 68588, USA

A. Houston.* Earth and Atmospheric Sciences, University of Nebraska-Lincoln, 305A Bessey Hall, Lincoln, NE 68588, USA. Corresponding author: Janell Walther (e-mail: Jwalther2@nebraska.edu).

*Adam Houston currently serves as an Associate Editor; peer review and editorial decisions regarding this manuscript were handled by Rocio Ballesteros.

Copyright remains with the author(s) or their institution(s). Permission for reuse (free in most cases) can be obtained from RightsLink. 
a significant say in deciding the importance of different lines of scientific research and technological development (Gregory and Miller 1998), as well as the policies guiding their use. The quality of input informing the development of and policies surrounding UAS will depend on publics' understanding of what drones are, what they could be used for, and what regulations already guide their use. The present research investigated current public understandings of UAS, especially their perceptions of the risks and benefits of weather drones as compared to other drones and examined how these understandings were formed.

Understanding how publics make sense of new science and technology in various contexts may increase societal well-being and improve decision-making through enhanced communication (Stocklmayer 2001). Scientists and technology designers can use information about how publics make sense of technology to more effectively engage the public in dialogues that inform the development of the technology and its regulation. Further, communication about science and technology can be designed to clarify and assist in the incorporation of facts and scientific findings to inform public opinion to achieve better decisions and outcomes. These dialogues, in turn, may result in enhanced public support by leading to regulation and technological UAS design that is responsive to the values various publics express (Hanson-Easey et al. 2015).

Public perceptions of drones: prior research

Public perceptions of UAS are often investigated in terms of military use (Kennedy and Rogers 2015). Perceptions of civilian UAS has been less studied, but some research does exist (Thompson and Bracken-Roche 2015; Winter et al. 2016). For example, Letterman et al. (2013) found that the general public appeared to have a low level of awareness of UAS; yet most of those surveyed supported use of UAS for search and rescue, fighting crime, and for commercial purposes. PytlikZillig et al. (2018) compared use of UAS for civilian security, economic, and environmental purposes and found especially high support for environmental purposes. Other research has demonstrated that use of UAS for personal or everyday use, particularly in shared public airspace or personal space, raises significant concerns (Murray 2012). Misuse and privacy are among the most common public concerns (Clothier et al. 2015; Rice et al. 2018). Thus, some have noted that expanding drone technology to civilian uses requires public support and a strong framework for regulation (Floreano and Wood 2015).

Given the growing use of UAS technology for civilian purposes (Volovelsky 2014; Clothier et al. 2015; Kennedy and Rogers 2015; Thompson and Bracken-Roche 2015; Winter et al. 2016), it is important to continue to study public perceptions of such uses and the factors influencing public support. Specifically, UAS technology is increasingly used for highaltitude ozone sampling and cloud mapping for weather research (Houston et al. 2012; Li et al. 2017). Increased use of drones for agricultural, commercial, environmental, and entertainment purposes adds more opportunity for civilian-purposed drone use (Floreano and Wood 2015). From the developers' perspective, a central benefit of drones for weather research is that drones can gather information where planes and people cannot, such as measuring drastic weather change in Antarctica (Darack 2012) and the air masses in and around severe storms (Elston et al. 2011). However, we know of no prior studies that have specifically explored public perspectives of weather drones.

\section{The present study}

This study examines how public audiences understand drones, including associated risks or concerns and benefits or hopes for the technology, and the bases of those understandings. To increase the utility of our results, we not only probed for the sources of hopes and concerns related to drone uses for weather research and other purposes, but also asked participants for their recommendations for how regulators, drone designers, and drone 
users could be responsive to their hopes and concerns. Given the little research existing on public perceptions of drones for specialized purposes, including weather drones, we formulated the following research questions:

RQ1: What are the natures of the hopes, concerns, and recommendations that people have for drone technology design, use, and regulation, when used for weather versus other civilian purposes?

RQ2: How and why do people form their attitudes, hopes, concerns, and recommendations about weather drones versus drones used for other purposes?

Next, we describe our study design, methods, and results. This is followed by a discussion of the limitations and potential implications of our results for drone regulators, designers, and users who may consider our results in their work and communication with the public.

\section{Methods}

To answer our research questions we used a grounded theory approach (Starks and Brown Trinidad 2007; Glaser and Strauss 2017) characterized by open-mindedness about how individuals viewed drone technology and its uses, as well as concerning how people's hopes, concerns, and recommendations might arise from sense-making activities. We gathered data through focus groups then, after intensive coding and analyses, developed key themes emerging from the data and integrated those themes with the extant literature, particularly based in public understanding of technological and scientific topics. This work was approved by the University of Nebraska-Lincoln Institutional Review Board, IRB ID 15696.

\section{Participants and recruitment}

We used a two-stage recruitment strategy designed to gather the perspectives of a wide variety of persons from across the US. In stage 1, we recruited 159 persons to complete a survey. Most $(n=118)$ participants were recruited through an invitation posted on Amazon's Mechanical Turk (MTurk). We also somewhat oversampled the views of persons $(n=29)$ living in proximity to the development of weather drones by posting our survey invite on Craigslist sites serving the five largest cites in each of Nebraska, Oklahoma, and Kentucky (the three home states of the universities involved in a project focused on the development of weather drones). Finally, survey participants and researchers on the project were encouraged to share the survey opportunity through their social media channels, resulting in a few more $(n=12)$ participants through referrals.

The project description and consent form invited interested participants to take a 30 min survey and informed them that, upon survey completion, they would have an approximately $20 \%$ chance of being involved in a $90 \mathrm{~min}$ remote or online focus group for which they would receive a $\$ 50$ Amazon gift card. The recruitment survey assessed general attitudes and demographics, and presented participants with a randomly selected set of two scenarios for drone use (weather or tornado drones and forecasting) and asked for their initial opinions related to these uses. We invited all survey participants with a valid email address to participate in focus groups via online video conference. Thirty participants agreed and participated in the focus groups.

The focus group participants included 12 men, 17 women, one unreported (59\% female); 77\% were white, $13 \%$ Black or African American, 7\% Asian, 7\% Spanish, Hispanic or Latinx from across the US. Ages ranged from 22 to 60 years (mean $=37.9, \mathrm{SD}=10.9$ years). Results from the recruitment survey indicated participants were generally quite favorable toward the use of weather drones (mean $(M)$ support for weather drones $=5.96$ on a 1-7 scale ranging 
Table 1. Scenarios by focus group.

\begin{tabular}{|c|c|c|c|c|c|c|c|c|}
\hline \multirow[b]{2}{*}{$\begin{array}{l}\text { Focus } \\
\text { group }\end{array}$} & \multicolumn{2}{|c|}{ Weather-related } & \multicolumn{6}{|c|}{ Other (non-weather-related) } \\
\hline & Tornado & Forecasting & $\begin{array}{l}\text { Commercial } \\
\text { delivery }\end{array}$ & $\begin{array}{l}\text { Water } \\
\text { sampling }\end{array}$ & Wildfires & Agriculture & $\begin{array}{l}\text { Video } \\
\text { production }\end{array}$ & $\begin{array}{l}\text { Infrastructure } \\
\text { inspection }\end{array}$ \\
\hline 1 & 1st & - & 2nd & - & - & - & - & - \\
\hline 2 & - & $1 \mathrm{st}$ & - & - & 2nd & - & - & - \\
\hline 3 & 2nd & - & 3rd & - & - & $1 \mathrm{st}$ & - & - \\
\hline 4 & - & $1 \mathrm{st}$ & - & - & - & - & 2nd & - \\
\hline 5 & 2nd & - & 3rd & 1st & - & - & - & - \\
\hline 6 & - & 2nd & 3rd & - & - & - & - & $1 \mathrm{st}$ \\
\hline 7 & - & 2nd & 1 st & - & - & - & - & - \\
\hline 8 & 1st & - & - & - & - & - & 2nd & - \\
\hline
\end{tabular}

from low to high support, $\mathrm{SD}=1.27)$, and comparatively less supportive of commercial uses (e.g., for package delivery drones, $M=4.24, \mathrm{SD}=1.76$ ). This suggests our focus group participants' attitudes were descriptively similar to those found in prior research (Clothier et al. 2015; Floreano and Wood 2015; PytlikZillig et al. 2018).

\section{Focus group methods and materials}

Our use of focus groups was designed to provide descriptive, nuanced descriptions of the breadth of extant public opinions of drone technology, including the hopes, concerns, and recommendations the public has for the design and regulation of UAS. Our follow-up questions and analyses probed how participants made sense of UAS technology, including the influences that took place prior to the focus group and during interaction with others as they compared and contrasted ideas with other focus group members. A benefit of focus groups is that they allow for the presence of meaningful, group interaction to responses of questions, and as such, they provide insight into how people think and talk about complex issues, allowing a researcher to see different points of view and how people navigate those differences (Morgan 1993).

Each focus group lasted 75-90 min and was conducted using web-based conferencing technology $\left(\mathrm{Zoom}^{1}\right)$. To ensure consistent questions were covered by each group, a facilitator guided the group following a semi-structured focus group process (Morgan 1993; Longhurst 2003). One or two technical experts with expertise in drone design and use for weather research purposes were also always present during the focus groups to answer questions and to assist the facilitator in posing probing or clarifying questions to the participants.

Two sets of scenarios were used: one scenario set focused on the use of drones for weather purposes (e.g., tornado, forecasting), and one set of scenarios focused on non-weather purposes, such as commercial delivery or infrastructure inspection (see Table 1) (full scenarios are available from the authors). All survey and focus group participants were asked to consider at least two scenarios, one from each set. ${ }^{2}$

After reading a scenario, participants were asked to discuss their hopes and concerns for the technology in the specific scenario. Follow up questions aimed to elicit factors contributing to forming those hopes and concerns. After the hopes and concerns discussion, participants were asked for their recommendations and, specifically, whether and how those who regulate, design, and use drones should be responsive to or take into account their hopes and concerns. After $60 \mathrm{~min}$ of discussion, participants were invited to ask any remaining questions they had to the group or experts, and then asked to complete a brief post-discussion survey.

${ }^{1}$ https:/|zoom.us/.

${ }^{2}$ Scenarios were randomly assigned during both the survey and the focus groups. Thus, the scenarios may or may not have already been viewed by individual focus group participants during their recruitment survey. 
Table 2. Coding categories and

exemplar codes.

\begin{tabular}{l}
\hline Scenarios \\
Agriculture \\
Commercial delivery \\
Tornado \\
Video production \\
Water sampling \\
Weather \\
Wild fires \\
Expressions \\
Concern \\
Hope \\
Question \\
Recommendation \\
Other \\
Topics \\
Airspace \\
Autonomy \\
Drone sabotage \\
Economic loss \\
Environmental/research \\
Forecasting for weather \\
General drone operations \\
Hobbyist \\
Identification of drones \\
Bad use or misuse \\
No concerns \\
Nuisance, visual pollution, proliferation \\
Operators of drones \\
Other - Location (of self-disclosure) \\
Pop culture \\
Population (e.g., urban vs. rural) \\
Privacy \\
Pros outweigh cons \\
Purpose of drones \\
Regulations \\
Safety/security \\
Self-disclosure of personal experience \\
Technology advancement \\
Trust of drone operators \\
\hline
\end{tabular}

\section{Data analysis}

Focus group discussions were transcribed verbatim and analyzed using Atlas.ti qualitative data analysis software. Qualitative analyses included the development of codes or themes as data were collected. These units of information were then placed into categories based on similar content and meaning using the constant comparison method (Lincoln and Guba 1985). Transcripts were coded in stages: first they were coded for emergent topic codes (e.g., "privacy", "efficiency"), and second for expression codes (e.g., "hope", "concern", "recommendation"). In a third round, the scenario under discussion was coded (e.g., "tornado research", "commercial delivery") to facilitate identification of differences associated with different drone purposes (MacQueen et al. 1998) (see Table 2 for examples).

During code development, two researchers coded three of the eight focus group transcripts. Themes emerging from the data and the coding for those transcripts were compared and discussed among the larger research team. At each coding discussion, independently assigned codes were reviewed to assess agreement and consistency, and codes were refined for clarity as needed. The remaining five transcripts were each coded 
by only one of the two researchers. After eight focus groups, we reached theoretical saturation in our sample, wherein no new themes were emerging in the latter groups that we had not heard in the earlier groups (Barbour 2013; Thornberg and Charmaz 2014). A constant comparative process allowed the research team to establish validity when no new codes were found (Suter 2009). In addition, tables showing the extent to which codes were likely to co-occur (generated by Atlas.ti) were used to help identify patterns among scenarios, expressions, and codes.

\section{Results}

Participant hopes, concerns, and recommendations (RQ1)

Examination of frequent hopes, concerns, and recommendations offered by our participants, and how these varied when considering weather UAS versus drones used for other purposes, revealed two findings especially worthy of note. First, when it came to weather drones and some other publicly valued purposes, people felt their hopes outweighed their concerns or that their concerns were less applicable to those purposes than to drones used for less-valued commercial purposes (e.g., moviemaking and delivery drones). That is, during the conversations among participants, "alternative perspectives" were often raised in response to concerns about drone use, to take into account participant desire to see the UASs used for desired purposes. A second major finding related to recommendations: participants did not want regulations to undermine the benefits weather drones and certain other benefits drones might provide. Although participants frequently expressed discomfort with making strong recommendations due to lack of knowledge, participants expressed numerous recommendations reflecting desires for drones to be used for the "greater good" and for the use of multi-way communication processes when making decisions about the regulation of drones.

\section{Hopes and benefits}

Participants were hopeful that UAS would lead to specific positive outcomes that were dependent upon their purpose. Table 3 gives exemplars of specific hopes and benefits mentioned related to different drone types. Emergent coding revealed hopes pertaining to gathering informative data (e.g., specific weather, agricultural, fire, and infrastructure data), while improving safety (e.g., of storm chasers, fire fighters, and infrastructure inspectors; as well as those in the paths of storms and fires) as well as increasing service efficiency (e.g., of deliveries, infrastructure inspections, and agricultural operations), access (e.g., due to drones being able to enter difficult to access or unsafe spaces), or quality (e.g., better videos).

Focus group participants indicated especially positive attitudes toward weather drones, as well as toward drones used for purposes such as water sampling, agriculture, and firefighting. Participants seemed to value these uses as advantageous to a larger common public good. For example, participants were hopeful about weather drones increasing forecasting capacity, public safety through research that would result in advance notification of dangerous storms, and the safety of storm watchers. As one participant noted:

... it [drone use] gets you much more realistic real time information other than having people driving along watching the tornadoes and the storms ... You're eliminating the risk of the storm watch, and you're getting much more developed information.

Discussions of drones used for fire-monitoring and fire-fighting seemed most similar to discussions of weather drones - again, with an emphasis on hopes for increased safety and information. For example, one participant said, "Knowing what way ... that 
Table 3. Examples of purpose-specific benefits in the identified major categories.

\begin{tabular}{|c|c|c|c|}
\hline & Information gathering & Safety & $\begin{array}{l}\text { Service efficiency, access, } \\
\text { quality }\end{array}$ \\
\hline Weather & $\begin{array}{l}\text { Real time information relating } \\
\text { to wind, temperature, } \\
\text { between ground level and } \\
\text { satellite level }\end{array}$ & $\begin{array}{l}\text { Storm chasers could be } \\
\text { further away from danger } \\
\text { Notify public sooner } \\
\text { of impending storms }\end{array}$ & $\begin{array}{l}\text { Decreased need to drive } \\
\text { to the storms, respond } \\
\text { to storms more quickly }\end{array}$ \\
\hline Fire & $\begin{array}{l}\text { Observe where the fire is, which } \\
\text { way fire is going, where the } \\
\text { hotspots are, at the same } \\
\text { time as getting wind speed, } \\
\text { weather information }\end{array}$ & $\begin{array}{l}\text { Keep fire fighters out of way } \\
\text { of danger } \\
\text { Notify public of danger sooner } \\
\text { thereby saving lives }\end{array}$ & $\begin{array}{l}\text { Aerial views without } \\
\text { needing manned } \\
\text { helicopters }\end{array}$ \\
\hline Agriculture & $\begin{array}{l}\text { Watch herds, observe fields } \\
\text { and crops }\end{array}$ & * & $\begin{array}{l}\text { Fewer personnel required } \\
\text { if drones are used }\end{array}$ \\
\hline $\begin{array}{l}\text { Water } \\
\text { sampling }\end{array}$ & $\begin{array}{l}\text { Sample water sources for } \\
\text { pollution }\end{array}$ & $\begin{array}{l}\text { Identify potentially harmful } \\
\text { water quality }\end{array}$ & $\begin{array}{l}\text { Access remote and hard- } \\
\text { to-access water sources }\end{array}$ \\
\hline Infrastructure & $\begin{array}{l}\text { Observe bridges, aerial views } \\
\text { of roads }\end{array}$ & $\begin{array}{l}\text { Identify dangerous } \\
\text { infrastructure } \\
\text { Personnel safer if } \\
\text { sending drone } \\
\text { to observe }\end{array}$ & Less personnel required \\
\hline Delivery & $\begin{array}{l}\text { Multi-purpose drones could } \\
\text { gather weather information } \\
\text { during deliveries }{ }^{\dagger}\end{array}$ & $\begin{array}{l}\text { Deliver to unsafe } \\
\text { neighborhoods } \\
\text { Keep delivery drivers } \\
\text { off the road }\end{array}$ & $\begin{array}{l}\text { Potentially quicker } \\
\text { deliveries }\end{array}$ \\
\hline Videos/movies & * & * & $\begin{array}{l}\text { More attractive, cheaper, } \\
\text { video captured }\end{array}$ \\
\hline
\end{tabular}

*No exemplars available.

${ }^{\dagger}$ Also a recommendation for reducing proliferation.

fire [is] moving too ... [drones] would do nothing but aid in a wildfire...". Participants also noted they felt it likely that drones could more easily (and again, more safely) access certain spaces, such as flying into storms, obtaining aerial views of fires, traversing difficult terrain, and making observations between the level of ground and satellite observations.

Efficiency or quality of service was less often mentioned during discussion of weather and fire drones; although a couple participants felt drones might be used to more quickly respond to such events. In contrast, use of drones for agriculture, commercial package delivery, and to create video footage very commonly resulted in participants focusing on potential efficiency benefits. In a discussion of agriculture uses, one participant noted "... if you have a drone that can see over a whole herd of cattle it might save some man power...". Similarly, relating to package delivery, a participant said, “... if it works correctly and people are actually getting what they want ... a lot quicker and ... a lot more reliable, that would be great..."; and relating to video drones, one noted that they can "make it cheaper for them [moviemakers] to get area shots".

Finally, safety and information gathering were also mentioned as benefits when it came to delivery and moviemaking drones, although less often. For example, one participant mentioned that delivery drones could foster safety of drivers by reducing the number of drivers on the road as delivery drivers are not needed. In addition, the safety of those making deliveries to dangerous areas (e.g., an unsafe neighborhood or across unsafe terrain or geographies) is enhanced by sending an unmanned drone instead. 


\section{Concerns and risks}

Categories of concern expressed by focus group participants were more numerous than hopes. These categories were largely consistent with prior research and related to issues of privacy, safety, proliferation, misuse, environmental impacts, technological limits and failures, and appropriate regulation. Table 4 provides representative quotes for each concern (which we will refer to as Qx, e.g., Q1 to reference quote 1). As shown, expressed concerns tended to be less specific to various drone purposes or uses, and participants commonly discussed their concerns in general terms rather than relating them to specific purposes. Table 4 also illustrates how the emphasis and importance of the concerns varied by drone purpose, as well as providing clues of counterarguments that some participants find to be convincing answers to concerns. A key finding in our study was that, during the discussions of public-good-focused drones (e.g., for weather and other valued purposes like agriculture and water sampling), participants frequently offered alternative perspectives undermining the relevance of certain concerns, thereby providing insight into how their opinions were formed by competing influences.

Participants expressed the most concerns during discussions of commercial use of drones for package delivery and making of movies. One survey respondent noted, "commercial use is much more open to debate, interpretation, and dependent upon regulations". Frequently mentioned were privacy concerns (Q1-Q5 in Table 4) about drone technology taking unwanted photos of people, property, and inside their house. On the other hand, when discussing valued purposes, such as weather forecasting and agricultural uses, participants mentioned that other technologies already infringe on one's privacy (Q6), or that the expectation was that technology would be used in very limited ways when used for certain purposes (e.g., only over the farmers' lands or cameras only pointing toward clouds) (Q7), or that one simply was not concerned about the issue in a particular context (Q8).

Commercial uses of drones also tended to elicit concerns (rather than hopes) for safety. Public safety concerns centered mostly on fears about drones falling from the sky (Q9, Q10) or crashing into other aircraft (Q11). A number of our participants were less worried about crashes in rural areas (e.g., for agriculture) than in areas where many people were present, such as in residential areas where deliveries might take place or at large gatherings of sports enthusiasts where drone moviemaking might take place. However, some participants noted crashing was a concern in rural areas. As one participant noted, "even in the most rural areas there's always somebody living there".

Although it was most typical that participants discussed how weather and fire drones could enhance safety, there were safety concerns discussed for weather and fire drones as well. Again, this was especially true if used in urban or populated areas. Most often, the concern with weather drones was related to if a storm might cause a drone to crash (Q9). Meanwhile, when it came to safety concerns related to fire drones, the concern was more related to other (e.g., hobbyist or moviemaking) drone users getting in the way of the fire responders as they use their drones to "get a better vantage point" on filming the fire (Q12). When it came to safety concerns, instead of undermining the relevance of the concerns, participants were willing to argue that technology could be designed, regulations set, and training provided to address their concerns (Q13-15).

Concerns about proliferation often were tied to safety concerns. Safety of airspace was recognized as an issue, especially if drones became more prolific (Q16). Participants also felt proliferation of drones could lead to noise and visual pollution (Q17), interference with the natural environment (Q27-28), and increased concerns about privacy (Q2). One participant was concerned with birds of prey potentially being hurt with increasing numbers drones in their airspace. Once again, however, when it came to uses of drones perceived as 
Table 4. Exemplar quotes for various concerns and alternate perspectives on those concerns.

\begin{tabular}{|c|c|c|}
\hline Concern & Exemplar topics & Alternative perspectives \\
\hline Privacy & $\begin{array}{l}\text { 1. "I don't want to be spied on, like look out my window and all of a } \\
\text { sudden a drone is zoning in...". } \\
\text { 2. "that's where it would start to concern me a little bit would be having } \\
\text { cameras everywhere..." } \\
\text { 3. "people have a reasonable expectation of privacy in their own } \\
\text { backyard" } \\
\text { 4. "This one [video drones] I feel like privacy is a much more pronounced } \\
\text { issue because it sounds like these drones can be much more accessible } \\
\text { and transportable as well". } \\
\text { 5. "I've seen news reports of civilians using drones to peek in people's } \\
\text { windows and that's just, again, that makes me really nervous". }\end{array}$ & $\begin{array}{l}\text { 6. "aerial views I don't think should be an issue cause Google's already } \\
\text { doing that [with] Google Maps..." } \\
\text { 7. "the cameras would be aimed at the clouds ... they would largely } \\
\text { be using scientific instruments to measure atmospheric pressure } \\
\ldots \text { they wouldn't be aimed at someone sitting by the pool..." } \\
\text { (weather) } \\
\text { 8. "help out the farmers and not make it so hard ... I don't really have } \\
\text { a problem with the privacy thing". (agriculture) }\end{array}$ \\
\hline Safety & $\begin{array}{l}\text { 9. "if the drone gets picked up by the tornado ... what, then, can a giant } \\
\text { chunk of metal with blades to fly do if picked up? ... in a more } \\
\text { populated area would increase my concern of somebody else getting } \\
\text { hurt from flying debris". (weather) } \\
\text { 10. "how are we going to make sure that somebody doesn't get hit by this } \\
\text { thing if it does come out of the sky?" } \\
\text { 11. "Airspace conflicting with manned aircraft, I think is my primary } \\
\text { concern". } \\
\text { 12. "local people in the area are just trying to use drones to get aerial } \\
\text { pictures ... And it's actually interfering with work and the safety of } \\
\text { those trying to control the fire". (video and fire) }\end{array}$ & $\begin{array}{l}\text { 13. "I think those things, autonomous [controls or fail-safes], work very } \\
\text { well with the limitations of heights so that you are not in the } \\
\text { airspace of other aircraft..." } \\
\text { 14. "I'm thinking for sure they [weather drones] are going to have a } \\
\text { transponder so that the FCT and commercial aircraft could pick } \\
\text { them up ... plus under some degree of air traffic control depending } \\
\text { on airspace they're in, I think that that's probably already } \\
\text { something that's been taken care of". } \\
\text { 15. "the height of flying } 2500 \text { feet is pretty high kind of close to } \\
\text { commercial flights ... [but] as long as it is regulated and this } \\
\text { operation is performed by competent people it shouldn't be a } \\
\text { concern..." }\end{array}$ \\
\hline Proliferation & $\begin{array}{l}\text { 16. "I would have a particular problem with a lot of drones flying over my } \\
\text { head. For safety, it would be a concern - I don't want to be attacked } \\
\text { by one". } \\
\text { 17. "visual pollution over, kind of protected land areas that are non- } \\
\text { motorized to begin with". } \\
\text { 18. "how prolific drones are is my main concern..." } \\
\text { 19. "one drone, is not a big deal ... I just don't know how they can be } \\
\text { controlled if there are a number of them". }\end{array}$ & $\begin{array}{l}\text { 20. "But the benefit of being able to test that water for pollution I think } \\
\text { would almost outweigh that visual pollution..." (water sampling) } \\
\text { 21. "You're eliminating the risk of the storm watch, and you're getting } \\
\text { much more developed information. This is an ethical limited use of } \\
\text { drones". (emphases added) (weather) }\end{array}$ \\
\hline Misuse & $\begin{array}{l}\text { 22. "what if ... it's a dirty drone and it has a bomb in it..." (movie) } \\
\text { 23. "... if they had a drone to monitor crops, they would be using that } \\
\text { drone to help them hunt". (agriculture) } \\
\text { 24. "I think that criminals will move first and use drones to } \\
\text { promote crime..." }\end{array}$ & $\begin{array}{l}\text { 25. "I don't think that we will ever get to that type of control within the } \\
\text { gun ownership, ownership of the vehicle, or even ownership of the } \\
\text { drone". } \\
\text { 26. "And you know it, with any technology or anything almost, there's } \\
\text { people that aren't going to follow the rules. No matter what it is. } \\
\text { People illegally drive without a license and stuff like that. We } \\
\text { shouldn't penalize the technology just because that happens - it } \\
\text { happens with everything". }\end{array}$ \\
\hline
\end{tabular}

. "that's where it would start to concern me a little bit would be having

"This one [video drones] I feel like privacy is a much more pronounced issue because it sounds like these drones can be much more accessible and transportable as well". "if the drone gets picked up by the tornado ... what, then, can a giant chunk of metal with blades to fly do if picked up? ... in a more

cal people in pictures ... And it's actually interfering with work and the safety of those trying to control the fire". (video and fire) "vy one". motorized to begin with".

"how prolific drones are is my main concern ..."

22. "what if ... it's a dirty drone and it has a bomb in it .." (movie) "... if they had a drone to monitor crops, they would be using that drone to help them hunt". (agriculture) 
Table 4. (concluded)

\begin{tabular}{|c|c|c|}
\hline Concern & Exemplar topics & Alternative perspectives \\
\hline Environment & $\begin{array}{l}\text { 27. "I'm just wondering about how it might interfere with wildlife..." } \\
\text { 28. "I don't want it to disturb birds ..." }\end{array}$ & $\begin{array}{l}\text { 29. "I really love ... it's really going to help people, animals, as well as } \\
\text { like for environmental health". }\end{array}$ \\
\hline $\begin{array}{l}\text { Technology } \\
\text { limits or } \\
\text { failure }\end{array}$ & $\begin{array}{l}\text { 30. "if it can be hacked or whatnot" } \\
\text { 31. "people tracking drones, shooting it down, stealing the stuff..." } \\
\text { 32. "are they gonna fly “em directly into the storm, or around the storm? } \\
\text { Fifty-five pounds, it's not gonna take much to blow that away". } \\
\text { (weather) } \\
\text { 33. "I think my main concern with it would be ... overreliance on it ... } \\
\text { if for some reason the drone doesn't work ... what would be your } \\
\text { backup plan?" (agriculture) }\end{array}$ & $\begin{array}{l}\text { 34. "Let's say ... it has some sort of a mechanical malfunction ... } \\
\text { or loses connection with the user; [maybe it could be programmed } \\
\text { so that] it knows where the user is enough to get back to it". } \\
\text { 35. "it's out over the water, for the water sample ... there's really no } \\
\text { concern". (water sampling) }\end{array}$ \\
\hline $\begin{array}{l}\text { Appropriate } \\
\text { regulation }\end{array}$ & $\begin{array}{l}\text { 36. "I like the idea of them being used as data collection and mine that data } \\
\text { for later use, and risk managements ... I do wonder about the } \\
\text { restrictions that the regulations would put on that application..." } \\
\text { (weather) } \\
\text { 37. "... how are they going to be able to keep it in their sight for that } \\
\text { amount of time at those altitudes I mean I can't see that far you know. } \\
\text { I just find that kind of difficult..." }\end{array}$ & - \\
\hline
\end{tabular}


contributing to public health and safety, participants seemed somewhat willing to set their concerns aside. For example, relating to the water sampling scenario, one participant mentioned that their own concerns were small in comparison to the potential benefits (Q20). When it came to drones purposed for the public good, participants tended to see those uses representing "limited" uses less relevant to their concerns about proliferation (Q21).

Concerns and doubts were also expressed about misuses of drones, such as if drones were used to transport and deliver bombs or to engage in other illegal activities (Q22-24). In contrast, some participants counter-argued that every technology could be misused and that fears of misuse should not prevent technological advancement (Q25-26).

Concerns also related to the capacities of drone technologies to achieve their purposes in a manner that was reliable and useful, such as if the technology was able to be hacked $(Q 30)$ or disrupted by humans because no human is on board (Q31), or unable to withstand storms $(\mathrm{Q} 32)$, or simply not entirely reliable $(\mathrm{Q} 33)$. In response to these concerns, other participants noted that technology can be programmed with backup technological solutions (Q34) or that certain uses make technological failures and other concerns less applicable (Q35). Finally, participants expressed concerns about regulations that, for example, require line of sight, interfering with the purposes of drones (Q36-37). These concerns led to recommendations, and so we discuss them in greater depth in the next section.

\section{Recommendations}

Participants' recommendations were connected to their hopes and concerns. For instance, one participant recommended that, although not intended for information gathering, commercial drones such as delivery drones could be multipurpose technologies, gathering weather data, for example, as they make their deliveries. This multi-use would also help reduce proliferation, which was one of the concerns. Participant recommendations especially focused on the need for multi-way communication and transparency, drone characteristics, flexible regulation that allows drones to achieve public good purposes, and pilot training. When asked who should be responsive to their hopes and concerns, participants uniformly pointed to regulators as those primarily responsible, although they also felt technology designers could also be responsive by designing technology with their concerns in mind, and users could be responsive by getting training and following regulations.

Communication from drone users to the public included having means for identifying drones when they are in use, and their purposes and plans. Participants discussed the need for identification of drones, whether through the design and characteristics of the drone itself, or through other means, such as public notification on a website or media release. They felt that identification would reduce safety, security, and privacy concerns and perhaps reduce the number of times drones are reported or "shot down" by individuals on the ground.

... We can look at a vehicle and tell what that vehicle is used for. ... It would be interesting if they could design drones in such a manner that they were known for emergency response or for data gathering.

To develop effective regulations, participants suggested collaborative efforts between government, coalitions, and companies using drones. Participants suggested that a government entity organize a working group or coalition to provide validity to the group, but that the group be made up of users from various fields. Further, participants noted the importance of including users and designers in regulation development.

The topic of regulation came up most often when discussing video production purposes or commercial delivery purposes. Participants wanted well-considered regulations to 
ensure safety. Coordination with the FAA (Federal Aviation Administration) and regulation were factors in alleviating concerns. Individuals saw a need for creating regulations, whether through the existing FAA or a new agency: "I can see a clear need for some kind of a new agency that looks at airspace in three dimensions at all times". Another participant noted, "Obviously the FAA ... they are the agency that we rely on for safety in flight and they should be the ones who create the regulations".

Especially when discussing public-good purposes of UAS, participants also expressed desire for regulation of safety without being overly restrictive. Participants suggested that essential regulations about drones should be centered on privacy protection, air traffic management, and user management. Comparisons of the purposes of drones, and the values of those purposes, appeared to give rise to how much and what types of regulation people reported was desirable.

... I would want to be a lot stricter about how commercial companies are using the drones and what kind of technology they can have on their drones. But for research [purposes], I'm definitely a lot more lenient. I would like ... the researchers to be able to get the data that they need.

Finally, operator training or licensure was a recommendation offered by many of our participants, as a way to alleviate many of their concerns.

\section{Processes contributing to public understanding of drones (RQ2)}

In the data presented above, it is clear that participants were forming their hopes and concerns for UAS use around UAS purposes. In addition, our focus group data suggest participants made sense of UASs through considering: (i) personal experiences, (ii) media representations, (iii) comparisons between technologies, and (iv) the trustworthiness (or distrustworthiness) of the users, regulators, and the drone technology itself. It did not seem that participants used vastly different sense-making processes to understand weather drones compared to other drones.

\section{Personal experiences}

Related to personal experiences, self-disclosure was used to articulate opinions and often came in the form of describing where one was from, such as living in a tornado-prone area. Personal experience and location came up most often with expression of hopes for improved weather forecasting.

I live in Texas and tornado country, I've witnessed tornadoes, I've had to take shelter from them many times. This is an ethical use of the technology because it gets you much more realistic real time information other than having people driving along watching the tornadoes and the storms.

\section{Media representations}

Beyond direct experience, media representations of a technology often impact how individuals understand, articulate, and debate science and technology issues (Nisbet et al. 2002). Thus, it was not surprising that individuals in our study referenced pop culture (e.g., fictional television shows like South Park) and news-like sources (e.g., Stormchasers reality television show) to frame their understanding and articulate their opinions. For example, one participant said, "I couldn't help but think of the movie Twister, ... I think just, not having, not putting human lives in danger just for the sake of gathering information". Participants often used media representations to describe their concerns, often in terms 
of privacy as they related their understanding of the technology and its implications to pop culture representations of the technology, for example:

I keep thinking back to that South Park episode where [drones] becomes a thing and everybody is ... using it just for their personal use, just to have fun. But it happens that they realize as they're flying around the city that they could spy on people.

These references to media and popular culture not only provided a way for participants to understand the technology, but also to describe their opinions, consistent with other research finding narrative representations and framing help to shape public opinion (Nisbet 2009).

\section{Comparisons between technologies}

Consistent with prior research, a third way that our focus group participants formed their views was by comparison between technologies, including comparing the differently purposed drones that we presented to them, but also comparing drones to more familiar technologies. For example, regarding privacy one participant noted,

I don't think that we have any reasonable expectation of privacy, that's not already been crossed by other technology ... there is no difference to me from the government satellites, for a drone, or somebody who is climbing a tree, birdwatching with ... a pair of binoculars.

Also, participants evoked discussion of other technologies and how these were regulated, as providing potential models for the regulation of drones.

... the FDA, there's restrictions on drugs, and how quickly they come onto the market ... But there are some cases where they say, ... this is a mercy rule, and we are going to relax the rules because the needs are so great ... it seems like, ok tornados, natural disasters and things like that, and would qualify ... as worth it to all of us to ease restrictions [on drone usage] for that purpose.

\section{Trustworthiness perceptions}

Perceptions of trustworthiness also played a large role in the formulation of hopes, concerns, and recommendations for our participants. Participants indicated they were simultaneously weighing how much they trusted those using the drones, those regulating the drones, and the drones themselves. A primary consideration related to trustworthiness of technology was reliability. In some cases, doubts about reliability decreased willingness to rely too much on the technology (see Table 4, Q33). Also, participants tended to view features of drones as enhancing their perceptions of the trustworthiness of the technology to fulfill a certain purpose; for example, one participant stated, "make [the drone] able to withstand certain temperature, weather, and any possible craziness that could happen up there while it's in use". On the other hand, when certain features, such as a camera, were used, participants' sometime trust decreased and concerns (e.g., with privacy) increased.

While the technology itself was important, participants indicated a need to trust users and regulators. Comments about the trustworthiness of users or pilots of drones tended to emphasize evaluations of user intentions and competencies. When it came to trusting the users of drones, people took into account the purposes for which the users wanted the drones, and generally saw use of drones for research as less selfish than commercial or delivery use. 
Participants also varied in their views of the trustworthiness of regulators. Some participants perceived regulators as potentially creating barriers to important uses; for example, "My concern [with the FAA] is ... that they will stay reasonable and ... help out the farmers and not make it so hard to regulate their crops using the new technology". Others indicated trust in regulators as they felt their concerns for safety could be better addressed by relevant experts involved in creating regulations than by less-knowledgeable everyday publics. For instance, one participant stated "For safety concerns, I do think it should be regulated by people who know what they are talking about ... like FAA and people who are well educated on it".

\section{Discussion}

This study's purpose was to explore public perceptions and understandings of drone technology, especially their understanding of weather drones as compared to other civilian drones, and the variety of ways publics come to these understandings. Perhaps the most significant result of our study is the evidence that people feel positively towards drones used for weather research purposes, and toward other drone uses that are perceived as for "the public good", such as drones used for firefighting or agriculture. Meanwhile, use of drones for purposes such as delivery and moviemaking, were not viewed as favorably and did not seem to elicit the same levels of support. This view of the importance of the purpose of the drones for affecting support is consistent with a prior study also finding drone purpose as a major predictor of support or resistance to drones (PytlikZillig et al. 2018). Purpose of drones impacted people's willingness to accept their use, the extent of their concerns, and for the regulations they felt should govern their use. For example, while some common overarching concerns about drone technology emerged in response to all scenarios, the "alternative perspectives" offered by our participants, and their willingness to accept less restrictive regulatory frameworks when noble purposes were considered, suggests some publics are willing to overlook their concerns for strong public good benefits.

The implications of public attention to drone purposes suggests that communicators should emphasize how use of drones benefits the public good. Meanwhile, regulations should balance safety with technology purposes so that regulations are not so restrictive that drones cannot fulfill their purposes. Participants therefore suggested developing regulations in partnership with users (e.g., hobbyist groups, research organizations, commercial organizations) to address future research, technology growth, and drone applications while addressing public concerns. Furthermore, participants offered a variety of ways to explain drone regulations that might vary by purpose or situation (such as in the section entitled "Comparisons between technologies" where participants discussed a "mercy rule"). Communicators can draw upon the sources participants are already using to form their understandings - such as familiar media representations and familiarity with prior technologies - to formulate communications readily understood by the public. Communications should focus on how regulations and design address public concerns, such as safety, air traffic, and privacy.

A second major finding relates to a greater understanding of public perceptions of benefits and risks and how the public forms these perceptions. Participants valued UAS benefits for information gathering, safety, and efficiency, although some benefits appear to be more relevant to certain types of drones than others (Table 3). Meanwhile, common concerns related to safety, privacy, proliferation, misuse, and technological limitations. When communicating about drone technologies, it is necessary to be cognizant of these benefits and concerns and the factors that moderate them. For example, some participants mentioned that their concerns would be lessened if UAS were to be used in rural rather than 
urban areas. Our research suggests that such concerns may be addressed by explaining how the drone technology or its regulation and the training of users impact the concerns, as well as by designing drones to be responsive to public values. For example, National Airspace Systems may focus on routing unmanned traffic over rural areas and keeping UAS clearly identifiable. Participants suggested that in-air drone identification might reduce uncertainty, alleviate concern over purpose, and build trust in the user. Participants suggested that this identification could be within the drone design (such as color, labeling) or a tool (such as a website). They also suggested information outreach about drone use in the area by alerting people of the flight location, purpose, how it is being used, and features (e.g., camera, heat technology features). In addition, privacy was among the most frequently mentioned concerns expressed by participants. This concern might be reduced with the elimination of the camera on the drone itself.

Finally, a third major finding was that trust in the technology and its users, as well as in regulators, were key factors in how individuals shape their opinions and understanding. This finding deserves further investigation in future studies. A number of the comments suggested the possibility of nonlinear relationships between trust in the various entities and willingness to support drones. That is, concerns about the trustworthiness of one entity (e.g., will users follow the height restrictions?) were sometimes countered by suggestions that trustworthiness of a different entity could compensate for that concern (e.g., the drones could be designed to not allow flight above a certain height). Meanwhile, other comments suggested public support sometimes might depend on high trustworthiness of multiple targets (such as Table 4 Q15 suggesting regulation and user competence was potentially equally important). Regardless, participants were evaluating the trustworthiness of all three entities and identified factors that might increase the trustworthiness of each, such as easy identification of drone purposes, required training of users, and regulators that collaboratively made policy.

\section{Limitations and future directions}

The focus groups were conducted until we reached saturation of themes, lending confidence to our understanding of the varieties of ways people form their understandings; however, our research touched upon a limited number of topics and uses of drones and in a limited population of the public. Further research should clarify and develop additional topics, such as understanding perceptions of different commercial uses of drones and probing more deeply into issues relating to different configurations of trust in targets related to drone technology. Furthermore, as shown in Table 4, there was variation in public opinions and perceptions that could be investigated in larger and more representative populations to determine if certain perspectives are more prominent than others under different conditions (e.g., in rural versus urban situations, or dependent upon who is using the drones). Our research did not examine differences between publics, such as pilots versus non-pilots, persons living in different geographical areas, or persons holding different political views. Given that the public is not a monolithic entity, future research is needed to compare between different stakeholders.

Nonetheless, by elucidating a number of public hopes, concerns, recommendations, and advancing understanding of how they formed these views, our results provide information worth considering during drone development, allowing more responsive developments of the technology and policies governing their use. In this way, drone technology might be built with the publics' values in mind, so that they too, feel a larger sense of buy-in into the technology (Hanson-Easey et al. 2015). Understanding public perceptions also may provide scientists and science communicators vocabularies and strategies for dialogue that further enhances their effective integration into society. 


\section{References}

Barbour, R. 2013. Introducing qualitative research: A student's guide. Sage, Thousand Oaks, Calif., USA.

Clothier, R.A., Greer, D.A., Greer, D.G., and Mehta, A.M. 2015. Risk perception and the public acceptance of drones. Risk Anal. 35(6): 1167-1183. doi: 10.1111/risa.12330. PMID: 25689883.

Darack, E. 2012. UAVs: The new frontier for weather research and prediction. Weatherwise, 65(2): 20-27. doi: 10.1080/00431672.2012.653935.

Elston, J.S., Roadman, J., Stachura, M., Argrow, B., Houston, A., and Frew, E. 2011. The tempest unmanned aircraft system for in situ observations of tornadic supercells: Design and VORTEX2 flight results. J. Field Rob. 28(4): 461-483. doi: 10.1002/rob.20394.

Floreano, D., and Wood, R.J. 2015. Science, technology and the future of small autonomous drones. Nature, 521(7553): 460-466. doi: 10.1038/nature14542. PMID: 26017445.

Glaser, B., and Strauss, A. 2017. Grounded theory: The discovery of grounded theory. Routledge, New York, N.Y., USA.

Gregory, J., and Miller, S. 1998. Science in public: Communication, culture and credibility. Perseus Publishing, Cambridge, Mass., USA.

Hanson-Easey, S., Williams, S., Hansen, A., Fogarty, K., and Bi, P. 2015. Speaking of climate change: A discursive analysis of lay understandings. Sci. Commun. 37(2): 217-239. doi: 10.1177/1075547014568418.

Houston, A.L., Argrow, B., Elston, J., Lahowetz, J., Frew, E.W., and Kennedy, P.C. 2012. The collaborative Colorado-Nebraska unmanned aircraft system experiment. Bull. Am. Meteorol. Soc. 93(1): 39-54. doi: 10.1175/ 2011BAMS3073.1.

Kennedy, C., and Rogers, J.I. 2015. Virtuous drones? Int. J. Hum. Rights, 19(2): 211-227. doi: 10.1080/ 13642987.2014 .991217$.

Letterman, C., Schanzer, D., Pitts, W., Ladd, K., Holloway, J., Mitchell, S., and Kaydos-Daniels, S.C. 2013. Unmanned aircraft and the human element: Public perceptions and first responder concerns. Report. Institute for Homeland Security Solutions, Duke University, Durham, N.C., USA. Available from https://sites.duke.edu/ihss/files/2013/06/ UAS-Research-Brief.pdf.

Li, X.-B., Wang, D.-S., Lu, Q.-C., Peng, Z.-R., Lu, S.J., Li, B., and Li, C. 2017. Three-dimensional investigation of ozone pollution in the lower troposphere using an unmanned aerial vehicle platform. Environ. Pollut. 224: 107-116. doi: 10.1016/j.envpol.2017.01.064. PMID: 28202268.

Lincoln, Y.S., and Guba, E.G. 1985. Naturalistic inquiry. Vol. 75. Sage, Thousand Oaks, Calif., USA.

Longhurst, R. 2003. Semi-structured interviews and focus groups. In Key methods in geography. Edited by N. Clifford and G. Valentine. Sage, London, UK. Vol. 3, pp. 143-156.

MacQueen, K.M., McLellan, E., Kay, K., and Milstein, B. 1998. Codebook development for team-based qualitative analysis. Field Methods, 10(2): 31-36. doi: 10.1177/1525822X980100020301.

Morgan, D.L. 1993. Successful focus groups: Advancing the state of the art. Sage, Thousand Oaks, Calif., USA.

Murray, P. 2012. U.S. supports some domestic drone use: But public registers concern about own privacy. Monmouth University Poll, West Long Branch, N.J., USA. Available from https://www.monmouth.edu/ polling-institute/documents/monmouthpoll_us_061212.pdf/.

Nisbet, M.C. 2009. Communicating climate change: Why frames matter for public engagement. Environ.: Sci. Policy Sustainable Dev. 51(2): 12-23. doi: 10.3200/ENVT.51.2.12-23.

Nisbet, M.C., Scheufele, D.A., Shanahan, J., Moy, P., Brossard, D., and Lewenstein, B.V. 2002. Knowledge, reservations, or promise?: A media effects model for public perceptions of science and technology. Commun. Res. 29(5): 584-608. doi: 10.1177/009365002236196.

PytlikZillig, L.M., Duncan, B., Elbaum, S., and Detweiler, C. 2018. A drone by any other name: Purposes, end-user trustworthiness, and framing, but not terminology, affect public support for drones. IEEE Technol. Soc. Mag. 37(1): 80-91. doi: 10.1109/MTS.2018.2795121.

Rice, S., Tamilselvan, G., Winter, S.R., Milner, M.N., Anania, E.C., Sperlak, L., and Marte, D.A. 2018. Public perception of UAS privacy concerns: A gender comparison. J. Unmanned Veh. Syst. 6(2): 83-99. doi: 10.1139/juvs-2017-0011.

Starks, H., and Brown Trinidad, S. 2007. Choose your method: A comparison of phenomenology, discourse analysis, and grounded theory. Qual. Health Res. 17(10): 1372-1380. doi: 10.1177/1049732307307031. PMID: 18000076.

Stocklmayer, S.M. 2001. The background to effective science communication with the public. In Science communication in theory and practice. Vol. 14. Edited by S.M. Stocklmayer, M.M. Gore, and C.R. Bryant. Springer, Dordrecht, the Netherlands. pp. 3-22.

Suter, B. 2009. Validity in qualitative research on personal relationships. Ky. J. Commun. 28(2): 77-96.

Thompson, S., and Bracken-Roche, C. 2015. Understanding public opinion of UAVs in Canada: A 2014 analysis of survey data and its policy implications. J. Unmanned Veh. Syst. 3(4): 156-175. doi: 10.1139/juvs-2015-0025.

Thornberg, R., and Charmaz, K. 2014. Grounded theory and theoretical coding. In The SAGE handbook of qualitative data analysis. Edited by U. Flick. Sage, Thousand Oaks, Calif., USA. pp. 153-169.

Volovelsky, U. 2014. Civilian uses of unmanned aerial vehicles and the threat to the right to privacy - An Israeli case study. Comput. Law Secur. Rev. 30(3): 306-320. doi: 10.1016/j.clsr.2014.03.008.

Winter, S.R., Rice, S., Tamilselvan, G., and Tokarski, R. 2016. Mission-based citizen views on UAV usage and privacy: An affective perspective. J. Unmanned Veh. Syst. 4(2): 125-135. doi: 10.1139/juvs-2015-0031. 